cells), working in concert with activated Kupffer cells, platelets, and regenerating hepatocytes. ${ }^{5}$

A desmoplastic response in hepatocellular carcinoma is not particularly prominent and has not been reported to be related to prognosis. On the other hand, the encapsulated hepatocellular carcinoma and the fibrolamellar carcinoma, which show a distinct stromal reaction, are known to carry a better prognosis. ${ }^{67}$ Evidence suggests that the myofibroblasts have a role in limiting tumour expansion and preventing metastasis by virtue of their physical effect and anticollagenolytic properties. ${ }^{89}$ In a recent report it was suggested that the ability of the hepatocellular carcinoma cells to digest the extracellular matrix was related to tumour aggression. ${ }^{10}$ The presence of myofibroblasts in hepatocellular carcinoma is therefore interesting and warrants further investigation.
1 Ahmed A. The myofibroblast in breast disease. Pathol Annu 1990;2:237-86.

2 Arteaga CL, Tandon AK, Hoff DD. Transforming growth factor beta: Potential antocrine growth inhibitor of oesfrogen receptor negative human breast cancer cells $\mathrm{Can}$ trogen receptor negative
cer Res $1987 ; 48: 3898-904$

3 Tsukes T, McNutt MA, Ross R. HHF35, a muscle actin specific monoclonal antibody. Am J Pathol 1987;127: s89-402.

4 Rudolph R, McClure WJ, Woodward M. Contractile fibroblasts in chronic alcoholic cirrhosis. Gastroenterology 1979;76:704-9.

5 Gressner AM, Bachem MG. Cellular sources of noncollagenous matrix proteins: role of fat-storing cells in fibrogenesis. Semin Liver Dis 1990;10:30-46.

6 Berman MM, Libbey NP, Foster JH. Hepatocellular carcinoma of polygonal cell type with fibrous stroma-an atypical variant with a favourable prognosis. Cancer 1980;46: 1448-55.

7 Hsu HC, Wu TT, Wu MZ: Tumour invasiveness and prognosis in resected hepatocellular carcinoma: clinical prognosis in resected hepatocellular carcinoma: clinical

8 and pathogenetic implications. Cancer 1988;61:2095-9. taneous metastasis of BL6 melanoma with inhibition of the taneous metastasis of BL6 melanoma with inhibition of the desmoplastic res

9 Barsky SH, Nelson LL, Levy VA. Tumour desmoplasia inhibits angiogenesis. Lancet 1987;ii:1336-7.

10 Grigioni WF, Garbisa S, D'Errico A. Evaluation of hepatocellular carcinoma aggressiveness by a panel of extracellular matrix antigens. Am J Pathol 1991;138: 647-54

\title{
Use of Romanowsky type (Diff-3) stain for detecting Helicobacter pylori in smears and tissue sections
}

\author{
A M Zaitoun
}

\begin{abstract}
A Romanowsky type (Diff-3) stain was used for identifying Helicobacter pylori in gastric biopsy specimens from 50 patients with ulcer and non-ulcer dyspepsia. Air dried smears were prepared from fresh biopsy tissue and histological sections were prepared from paraffin wax processed tissue. The Diff-3 technique is accomplished in five steps and takes about 30 seconds. Results using the Diff-3 stain correlated $100 \%$ with those using the Giemsa stain. The Diff-3 stain is reliable, simple, rapid, easy and clean, and smears prepared from fresh biopsy tissue can be examined and an immediate report given. The method is recommended for the identification of $H$ pylori in smears prepared from fresh tissue as well as in sections prepared from processed tissue.
\end{abstract}

Pathology

Qassimi Hospital, PO

Box 3500 Sharjah,

United Arab Emirates

A M Zaitoun

Correspondence to:

Dr A M Zaitoun

Accepted for publication

23 September 1991
Many invasive and non-invasive techniques are currently, used for research into the natural history of Helicobacter pylori. Recent interest has focused on finding a simple and quick test for the detection of $H$ pylori in gastric biopsy specimens. ${ }^{1}$
Histological detection of $H$ pylori in gastric biopsy specimens can be achieved using several techniques, including the Warthin-Starry silver stain, ${ }^{2}$ Giemsa, ${ }^{3}$ half-Gram, ${ }^{4}$ Gimenéz, Cresyl fast violet, ${ }^{6}$ Brown-Hopps ${ }^{7}$ and immunohistochemical methods. ${ }^{8}$

\section{Methods}

Gastric biopsy specimens from 50 patients with ulcer and non-ulcer dyspepsia were studied by histological and cytological techniques for the presence of $H$ pylori. Gastric biopsy specimens received in this laboratory include one antral biopsy used for direct smear, urease test, and culture, and a second biopsy specimen for the preparation of histological sections. After grinding a biopsy fragment in a sterile grinder air dried smears are prepared and stained by Diff3 (available from Gainland Chemical Company, Factory Road, Sandycroft, Deeside, Clwyd, Wales). Gastric biopsy specimens for histopathological examination are processed in formalin, and sections $4 \mu \mathrm{m}$ thick are cut, dewaxed, and stained by the Diff- 3 and Giemsa stains. 
The Diff- 3 technique is accomplished in five steps, taking about 30 seconds:

1 Fixation of air dried smears in methyl alcohol- 4 dips of 1 second.

2 Buffered eosin solution (solution A) -4 dips of 1 second.

3 Buffered polychromed methylene blue (solution B) -5 dips of 1 second.

4 Rinse and dry.

5 Clear in xylene and mount.

Slides are examined using a $\times 40$ objective lens.

\section{Results}

Figures 1 and 2 show the characteristic morphology of $H$ pylori curved bacilli in histological sections and cytological smears, respectively. Fourty two biopsy specimens out of 50 were positive for $H$ pylori by both the Diff-3 and Giemsa stains.

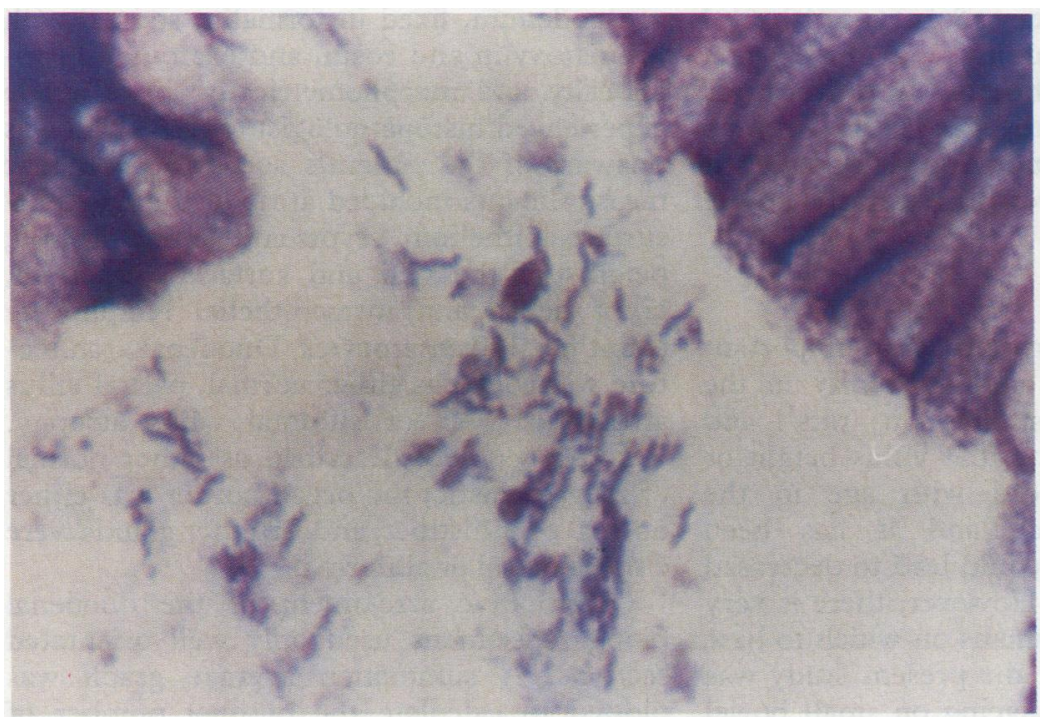

Figure $1 \quad H$ pylori in section prepared from formalin fixed gastric biopsy specimen (Diff-3 stain).

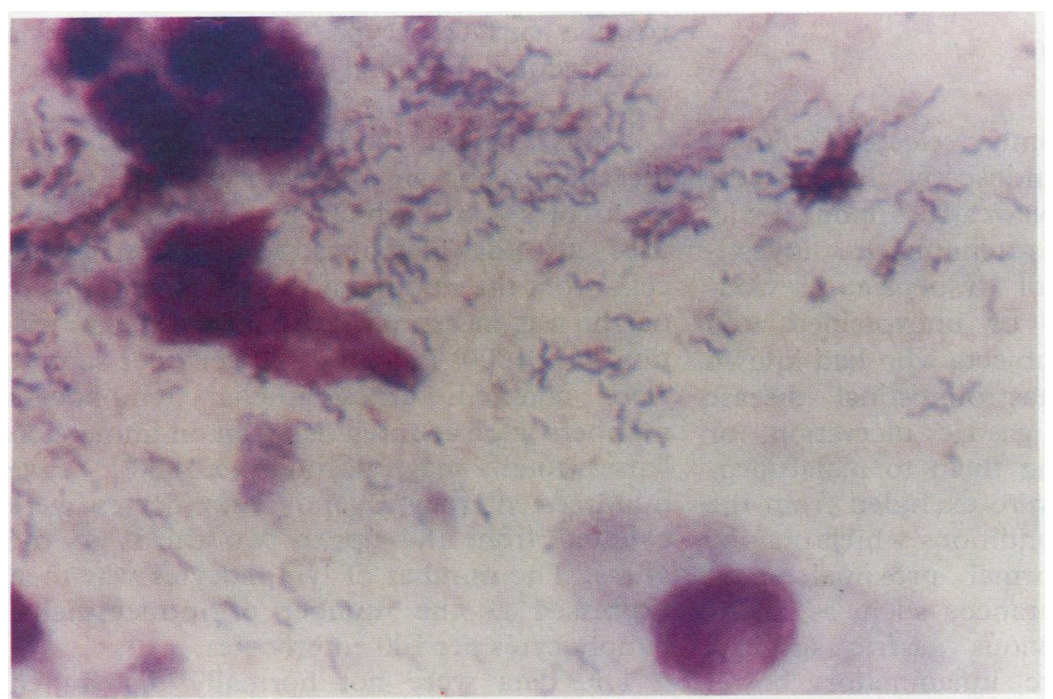

Figure $2 \quad H$ pylori in air dried smear prepared from fresh gastric biopsy specimen (Diff-3 stain).

\section{Discussion}

The Warthin-Starry silver stain was first used for the detection of $H$ pylori in histological sections prepared from gastric biopsy specimens. $^{2}$ This has proved technically difficult. Various other stains ${ }^{3-7}$ are quicker and simpler than the Warthin-Starry silver stain. Of these, currently the most widely used is the modified Giemsa stain. ${ }^{3}$

To check the accuracy of the Diff-3 stain for identifying $H$ pylori in gastric biopsy specimens Diff- 3 and Giemsa stained sections in 50 patients with ulcer and non-ulcer dyspepsia were compared. Results obtained by the Diff-3 stain correlated $100 \%$ with those obtained using the Giemsa stain. However, the advantage of the Diff-3 stain over the Giemsa stain is that it is a rapid procedure which takes less than one minute compared with 30 minutes using Giemsa stain. ${ }^{3}$ It is also less time consuming for preparing the solutions and bacteria are better visualised with the Diff-3 stain due to the tinctorial quality of the organisms. Both Diff-3 and Giemsa stains are cheap and readily available to any laboratory.

Because the Diff- 3 stain can be performed within 30 seconds and is clean and easy to use, this has a practical advantage for the gastroenterologist who requires a rapid and specific technique for detection of $H$ pylori in gastric biopsy specimens from patients with dyspepsia. Specimens obtained by clinicians are immediately brought to the pathology laboratory where air dried smears are prepared, stained, and examined by the pathologist with an immediate report given over the telephone. This may help the gastroenterologist to give the appropriate treatment immediately, thereby obviating another visit to the clinic.

The Diff- 3 stain has proved to be reliable, quick, and easy for identifying $H$ pylori in smears as well as in histological sections from gastric biopsy specimens.

1 Thillainayagam AV, Arvind AS, Cook RS, Harrison IG Tabagchali S, Farthing MJG. Diagnostic efficiency of an ultrarapid endoscopy room test for Helicobacter pylori. Gut 1991;32:467-9.

2 Marshall BJ, Warren JR Jr. Unidentified curved bacilli in the stomach of patients with gastric and peptic ulceration. the stomach of patients wit

3 Gray SF, Wyatt JI, Rathbone BJ. Simplified technique for identifying Campylobacter pyloridis. J Clin Pathol 1986; 39:1279.

4 Trowell JE, Yoong AKH, Saul KJ, Gant PW, Bell GD. Simple half-gram stain fo showing presence of Campylobacter pyloridis in sections. J Clin Pathol 1987; 40:702.

5 McMullen L, Walker MM, Bain LA, Karim QN, Baron JH. Histological identification of Campylobacter using Gimenez technique in gastric antral mucosa. J Clin Patho 1987;40:464-5.

6 Burnett RA, Brown IL, Findlay J. Cresyl fast violet staining method for Campylobacter like organisms. J Clin Pathol 1987;40:353.

7 Westblom TU, Madan E, Kemp J, Subik MA. Improved visualisation of mucus penetration by Campylobacter
pylori using a Brown-Hopps stain. J Clin Pathol 1988; p1:232.

8 Cartun RW, Pedersen CA, Krzymowski GA, Berman MM Immunocytochemical detection of Helicobacter pylori in Immunocytochemical detection of Helicobacter pylori in 1990;43:518. 